\title{
Simultaneous Detection and Differentiation of Highly Virulent and Classical Chinese-Type Isolation of PRRSV by Real-Time RT-PCR
}

\author{
Shuqi Xiao, Yaosheng Chen, Liangliang Wang, Jintao Gao, \\ Delin Mo, Zuyong He, and Xiaohong Liu \\ State Key Laboratory of Biocontrol, School of Life Sciences, Sun Yat-sen University, Guangzhou 510006, China \\ Correspondence should be addressed to Xiaohong Liu; xhliu@163.net
}

Received 24 November 2013; Accepted 15 May 2014; Published 12 June 2014

Academic Editor: Yong-Suk Jang

Copyright (C) 2014 Shuqi Xiao et al. This is an open access article distributed under the Creative Commons Attribution License, which permits unrestricted use, distribution, and reproduction in any medium, provided the original work is properly cited.

Porcine reproductive and respiratory syndrome (PRRS) is a leading disease in pig industry worldwide and can result in serious economic losses each year. The PRRS epidemic situation in China has been very complicated since the unprecedented largescale highly pathogenic PRRS (HP-PRRS) outbreaks in 2006. And now the HP-PRRS virus (HP-PRRSV) and classical North American type PRRSV strains have coexisted in China. Rapid differential detection of the two strains of PRRSV is very important for effective PRRS control. The real-time RT-PCR for simultaneous detection and differentiation of HP-PRRSV and PRRSV by using both SYBR Green and TaqMan probes was developed and validated. Both assays can be used for rapid detection and strainspecific identification of HP-PRRSV and PRRSV. However, the TaqMan probe method had the highest detection rate whereas the conventional RT-PCR was the lowest. The real-time RT-PCR developed based on SYBR Green and TaqMan probe could be used for simultaneous detection and differentiation of HP-PRRSV and PRRSV in China, which will benefit much the PRRS control and research.

\section{Introduction}

Porcine reproductive and respiratory syndrome (PRRS) is widely accepted as being one of the most economically important diseases affecting swine industry [1]. In 2006 there was an unparalleled large-scale outbreak of the so-called high fever disease in most provinces of China that affected more than 2,000,000 pigs, leading to concerns within the global swine industry and in relation to public health [2-4]. In March 2007 the disease was identified in the Hai Duong province of Vietnam and it spread countrywide affecting more than 65,000 pigs $[5,6]$. The outbreaks caused extensive concern worldwide [7]. Studies demonstrated that highly virulent porcine reproductive and respiratory syndrome virus (HP-PRRSV) was the major causative pathogen of the socalled high fever disease [2]. Genetic analysis indicated that the HP-PRRSVs isolated from China and Vietnam shared a discontinuous deletion of 30 aa in nonstructural protein 2 (NSP2), as compared with the North American type PRRSV strains (NA PRRSV) $[2,5,8]$. Since 2006, the HP-PRRSV and classical North American type PRRSV strains coexist in China. Now PRRS epidemic situation is very complicated in China, of which the predominant form is the HP-PRRSV. Rapid differential detection of the two strains of PRRSV is very important for effective PRRS control. Therefore, it is imperative to develop an assay for simultaneous detection and strain identification of HP-PRRSV and PRRSV.

The current immunoassay, such as immunohistochemistry and serological methods, cannot differentiate between the two strains of PRRSV. Conventional RT-PCR is timeconsuming, lowly sensitive, and also prone to contamination. The development of real-time RT-PCR technology offers the opportunity for more rapid, sensitive, and specific detection of virus. The current two major genotypes, the European (EU) and the North American (US) strains, have been rapidly identified by SYBR Green-based or TaqMan probe-based real-time RT-PCR assay [9-11]. A specific TaqMan probe realtime RT-PCR has been developed for assaying the HP-PRRSV 
TABLE 1: Primers and probes used in the real-time RT-PCR and conventional RT-PCR assays.

\begin{tabular}{|c|c|c|c|c|}
\hline \multirow{2}{*}{ Primers and probes } & & \multirow{2}{*}{ Sequences $\left(5^{\prime}-3^{\prime}\right)$} & \multicolumn{2}{|c|}{ Products (bp) } \\
\hline & & & HP-PRRSV & PRRSV \\
\hline \multirow{2}{*}{ Conventional RT-PCR } & NSP2-F & AACACCCAGGCGACTTCA & \multirow{2}{*}{787} & \multirow{2}{*}{874} \\
\hline & NSP2-R & GCATGTCAACCCTATCCCAC & & \\
\hline \multirow{2}{*}{ Real-time RT-PCR } & NSP2-qF & GTGGGTCGGCACCAGTT & \multirow{2}{*}{85} & \multirow{2}{*}{172} \\
\hline & NSP2-qR & GACGCAGACAAATCCAGAGG & & \\
\hline \multirow{3}{*}{ Probes } & $\mathrm{Pb}-\mathrm{H}$ & FAM-CGCGTAGAACTGTGACAACAACGCTGA-TAMRA [12] & & \\
\hline & $\mathrm{Pb}-\mathrm{N}$ & HEX-AAAATTGGCTCACTCAAGGGCGTCA-TAMRA & & \\
\hline & $\mathrm{Pb}$-all & FAM-CACAGTTCTACGCGGTGCAGG-TAMRA & & \\
\hline
\end{tabular}

[12], but it is not able to differentially detect the HP-PRRSV and PRRSV.

In this research, the real-time RT-PCR for simultaneous detection and differentiation of HP-PRRSV and PRRSV by using both SYBR Green and TaqMan probe was developed and validated. These two methods provided alternative diagnostic assays in diverse PRRSV epidemiological circumstances.

\section{Materials and Methods}

2.1. Virus Strains and Clinical Samples. HP-PRRSV (GD and $\mathrm{XH})$ and PRRSV (CH-1a) virus strains were kindly supplied by Dr. Guihong Zhang (South China Agricultural University, China). PRRSV (CC), PRV, FPV, and FCV were kindly provided by Laboratory Animal Center in Jilin University, China. 39 and 477 serum samples were obtained from 6 pig farms in South China in 2008 and 2011, respectively. 15 sera as described previously were from pigs experimentally infected with HP-PRRSV and PRRSV [13]. The viral RNA of the virus-infected cell culture and serum was extracted by using QIAamp Viral RNA Mini Kit according to the manufacturer's instruction (Qiagen). First-strand cDNA was synthesized using the extracted total RNA and AMV Reverse Transcriptase from Reverse Transcription System of Promega according to the manufacturer's instruction (Promega).

2.2. PCR Primers and Probes. The difference of genome sequence between the HP-PRRSV and PRRSV was the 87base deletion in the fixed site in NSP2 gene [2, 12]. After aligning $20 \mathrm{HP}-\mathrm{PRRSV}$ and PRRSV strains isolated from China and the US strain (VR-2332) sequences obtained from the NCBI database, the NSP2 region was selected to design an assay for discriminating between HP-PRRSV and PRRSV strains. The differential detection based on real-time RT-PCR using SYBR Green I and TaqMan probes was performed employing the same primer pair (Table 1). Real-time RT-PCR for PRRSV detection based on dual-colour TaqMan probes was performed using strain-specific probes including a $\mathrm{Pb}-\mathrm{H}$ (only detecting HP-PRRSV strain) [12], Pb-N (only detecting PRRSV strain), and Pb-all (simultaneously detecting both HP-PRRSV and PRRSV strains) (Table 1).

SYBR Green I real-time PCR was carried out using SYBR Premix Ex Taq (TaKaRa) and the LightCycler 480 RealTime PCR System (Roche Applied Science). Amplification was performed in a $10 \mu \mathrm{L}$ reaction mixture containing $5.0 \mu \mathrm{L}$ SYBR Premix Ex Taq $(2 \times), 0.2 \mu \mathrm{L}$ of each forward (NSP2$\mathrm{qF})$ and reverse (NSP2-qR) primer $(10 \mu \mathrm{M}), 1.5 \mu \mathrm{L}$ cDNA or plasmid DNA, and 3.1 $\mu \mathrm{L} \mathrm{H2O}$. The amplification conditions were $95^{\circ} \mathrm{C}$ for $10 \mathrm{~s}$, followed by 40 cycles of $95^{\circ} \mathrm{C}$ for $5 \mathrm{~s}$ and $60^{\circ} \mathrm{C}$ for $40 \mathrm{~s}$. Fluorescent signal was detected for each cycle at the end of the $60^{\circ} \mathrm{C}$ extension step. For each assay, a standard curve was generated with 10 -fold serially diluted plasmid standards of $10^{2}-10^{6}$ copies $/ \mu \mathrm{L}$. Meanwhile positive and negative reference samples were detected along with unknown samples. After 40 amplification cycles, melting curve analysis was carried out with the conditions of $95^{\circ} \mathrm{C}$ for $1 \mathrm{~s}$ and $60^{\circ} \mathrm{C}$ for $15 \mathrm{~s}$ and then increased to $95^{\circ} \mathrm{C}$ while continuously collecting the fluorescent signal. The melting temperature (Tm) of each strain was analyzed to verify the PRRSV type.

The $10 \mu \mathrm{L}$ duplex TaqMan probe real-time PCR reaction mixtures contained 5.0 $\mu \mathrm{L}$ Premix Ex Taq $(2 \times)$ (TaKaRa), $0.2 \mu \mathrm{L}$ of each forward (NSP2-qF) and reverse (NSP2-qR) primer $(10 \mu \mathrm{M}), 0.2 \mu \mathrm{L}$ of each probe $(\mathrm{Pb}-\mathrm{H}$ and $\mathrm{Pb}-\mathrm{N}$ or $\mathrm{Pb}$-all and $\mathrm{Pb}-\mathrm{N}, 10 \mu \mathrm{M}), 1.5 \mu \mathrm{L}$ cDNA or plasmid DNA, and $2.7 \mu \mathrm{L} \mathrm{H}_{2} \mathrm{O}$. The amplification conditions were $95^{\circ} \mathrm{C}$ for $10 \mathrm{~s}$, followed by 45 cycles of $95^{\circ} \mathrm{C}$ for $5 \mathrm{~s}$ and $60^{\circ} \mathrm{C}$ for $40 \mathrm{~s}$. For each assay, a standard curve was generated with 10 fold serially diluted plasmid standards of $10^{1}-10^{6}$ copies $/ \mu \mathrm{L}$. The FAM (6-carboxyfluorescein) and HEX (hexachloro-6carboxyfluorescein) signals were detected for each cycle at the end of the $60^{\circ} \mathrm{C}$ extension step.

\subsection{Conventional RT-PCR and Preparation of Standard Plas-} mid DNA. The conventional RT-PCR was performed by using the NSP2-F and NSP2-R primers described in Table 1. $10 \mu \mathrm{L}$ reaction mixture contains $0.5 \mu \mathrm{L}$ cDNA, $5.0 \mu \mathrm{L} 2 \times \mathrm{PCR}$ reaction mix, $0.4 \mu \mathrm{L}$ NSP2-F $(10 \mu \mathrm{M})$ primer, $0.4 \mu \mathrm{L}$ NSP2-R $(10 \mu \mathrm{M})$ primer, $0.1 \mu \mathrm{L}$ Taq DNA polymerase $(2.5 \mathrm{U} / \mu \mathrm{L})$, and $3.6 \mu \mathrm{L} \mathrm{H}_{2} \mathrm{O}$. The negative controls included the reagents without cDNA template. The reaction mixtures were performed at the amplification condition: $95^{\circ} \mathrm{C}$ for $3 \mathrm{~min}$, followed by 30 cycles of $94^{\circ} \mathrm{C}$ for $30 \mathrm{~s}, 60^{\circ} \mathrm{C}$ for $30 \mathrm{~s}$, and $72^{\circ} \mathrm{C}$ for $1 \mathrm{~min}$, and a final extension step of $5 \mathrm{~min}$ at $72^{\circ} \mathrm{C}$. The PCR products were detected by $1.5 \%$ agarose gel electrophoresis in $1 \times$ TAE. Then the PCR products were cloned into the plasmid pMD20$\mathrm{T}(\mathrm{TaKaRa})$ and propagated in competent Escherichia coli DH5 $\alpha$ cells according to the manufacturer's instructions. Plasmid DNA was purified using the E.Z.N.A. Plasmid Mini 
TABLE 2: Intra- and interassay reproducibility of real-time PCR.

\begin{tabular}{|c|c|c|c|c|c|c|c|}
\hline \multirow{2}{*}{$\begin{array}{l}\text { Concentration of standard } \\
\text { plasmid (copies } / \mu \mathrm{L})\end{array}$} & \multirow{2}{*}{$n$} & \multicolumn{3}{|c|}{ Intra-assay (Cp) } & \multicolumn{3}{|c|}{ Interassay $(\mathrm{Cp})$} \\
\hline & & Mean & $\mathrm{SD}$ & CV (\%) & Mean & $\mathrm{SD}$ & $\mathrm{CV}(\%)$ \\
\hline \multicolumn{8}{|l|}{ HP-PRRSV (SYBR) } \\
\hline $10^{6}$ & 3 & 14.96 & 0.02 & 0.13 & 14.82 & 0.29 & 1.96 \\
\hline $10^{4}$ & 3 & 21.78 & 0.04 & 0.18 & 21.49 & 0.57 & 2.65 \\
\hline $10^{2}$ & 3 & 28.5 & 0.16 & 0.56 & 28.48 & 0.27 & 0.95 \\
\hline \multicolumn{8}{|l|}{ PRRSV (SYBR) } \\
\hline $10^{6}$ & 3 & 15.47 & 0.02 & 0.13 & 15.75 & 0.31 & 1.97 \\
\hline $10^{4}$ & 3 & 22.55 & 0.05 & 0.22 & 22.71 & 0.19 & 0.84 \\
\hline $10^{2}$ & 3 & 29.6 & 0.01 & 0.03 & 29.96 & 0.34 & 1.13 \\
\hline \multicolumn{8}{|l|}{ HP-PRRSV (FAM) } \\
\hline $10^{6}$ & 3 & 15.9 & 0.02 & 0.13 & 15.98 & 0.06 & 0.38 \\
\hline $10^{4}$ & 3 & 22.51 & 0.01 & 0.04 & 22.63 & 0.15 & 0.66 \\
\hline $10^{2}$ & 3 & 29.71 & 0.02 & 0.07 & 29.59 & 0.17 & 0.57 \\
\hline \multicolumn{8}{|l|}{ PRRSV (HEX) } \\
\hline $10^{6}$ & 3 & 16.59 & 0.15 & 0.90 & 16.47 & 0.04 & 0.24 \\
\hline $10^{4}$ & 3 & 23.41 & 0.09 & 0.38 & 23.44 & 0.37 & 1.58 \\
\hline $10^{2}$ & 3 & 29.75 & 0.04 & 0.13 & 29.56 & 0.28 & 0.95 \\
\hline
\end{tabular}

Kit I (Omega) and quantified by measuring $\mathrm{OD}_{260}$ using spectrophotometer ND-1000 (Wilmington, USA).

\section{Results and Discussion}

3.1. SYBR Green I Real-Time PCR. 10-fold serial plasmid dilutions were tested and used to construct the standard curve. The generated standard curve covered a linear range of $3.93 \times 10^{2}$ to $3.93 \times 10^{6}$ copies $/ \mu \mathrm{L}$ for HP-PRRSV and $8.56 \times 10^{2}$ to $8.56 \times 10^{6}$ copies/ $\mu \mathrm{L}$ for PRRSV. Both standard curves had a slope of -3.410 to -3.443 and an efficiency of 1.964 to 1.952 , which indicate a high PCR efficiency of the experiment (Figures 2(a) and 2(b)). The amplification with primers NSP2-qF and NSP2-qR yielded 85 bp and $172 \mathrm{bp}$ amplified product within NSP2 of both HP-PRRSV (GD) and PRRSV (CH-1a), respectively (Figure 1), which was sufficient to discriminate between melting peaks of the two PRRSV strains. The mean and standard deviation of Tm of HPPRRSV and PRRSV were $85.17 \pm 0.12^{\circ} \mathrm{C}$ and $87.27 \pm 0.07^{\circ} \mathrm{C}$, respectively (Figure $3(\mathrm{~b})$ ).

3.2. TaqMan Probe Real-Time PCR. The generated standard curve covered a linear range of $3.93 \times 10^{1}$ to $3.93 \times 10^{6}$ copies/ $\mu \mathrm{L}$ for HP-PRRSV and $8.56 \times 10^{1}$ to $8.56 \times 10^{6}$ copies/ $\mu \mathrm{L}$ for PRRSV. Both standard curves had a slope of -3.256 to -3.400 and an efficiency of 2.028 to 1.968 , which indicate a high PCR efficiency of the experiment (Figures 2(c) and 2(d)). Two TaqMan probes specific to HP-PRRSV and PRRSV strains combined in duplex real-time PCR system can specifically detect the two PRRSV strains. When the two TaqMan probes of $\mathrm{Pb}-\mathrm{H}$ (FAM) and $\mathrm{Pb}-\mathrm{N}$ (HEX) were combined in a duplex real-time PCR system, only the FAM fluorescent signal could be observed in the template of

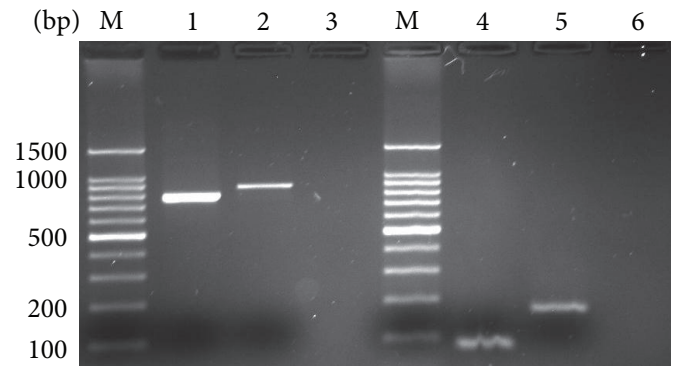

FIGURE 1: Conventional PCR results of PRRSV NSP2 gene. M: 100 bp marker; 1 and 4: HP-PRRSV (GD) strain; 2 and 5: PRRSV (CH-la) strain; 3 and 6: negative.

GD HP-PRRSV strain, and only the HEX fluorescent signal could be observed in the template of CH-la PRRSV strain (Figure 4). However, when $\mathrm{Pb}-\mathrm{N}$ (HEX) and $\mathrm{Pb}$-all (FAM) were combined in a duplex real-time PCR system, only HEX fluorescent signal could be observed when the template was CH-la PRRSV strain, and FAM fluorescent signal could be observed when the templates were GD and $\mathrm{CH}$-1a strains (Figure 4).

3.3. Validation of Real-Time PCR Assay. Specificity of realtime PCR using SYBR Green I and TaqMan probe was determined by analyzing nucleic acid extracts of other viruses (PRV, FPV, and FCV), host cells (Marc145, PK15), and $\mathrm{H}_{2} \mathrm{O}$. The results of the specificity test of the two methods showed that there were no cross-amplifications from other viruses or host cells (Figures 3(a) and 4), which confirmed that the primers and probes used in this study were highly specific for both HP-PRRSV and PRRSV. 
TABLE 3: Detection results of samples by conventional and real-time PCR.

\begin{tabular}{|c|c|c|c|c|c|c|c|}
\hline \multirow{3}{*}{ Samples } & \multirow{3}{*}{ Number } & \multicolumn{6}{|c|}{ Methods } \\
\hline & & \multicolumn{2}{|c|}{ Conventional PCR } & \multicolumn{2}{|c|}{ SYBR Green I } & \multicolumn{2}{|c|}{ TaqMan probe } \\
\hline & & HP-PRRSV & PRRSV & HP-PRRSV & PRRSV & HP-PRRSV & PRRSV \\
\hline Reference strains & 4 & 2 & 2 & 2 & 2 & 2 & 2 \\
\hline Serum 1 & 15 & 6 & 4 & 6 & 5 & 6 & 6 \\
\hline Serum 2 & 39 & 0 & 5 & 0 & 6 & 0 & 8 \\
\hline Serum 3 & 477 & 2 & 0 & 19 & 0 & 34 & 7 \\
\hline
\end{tabular}

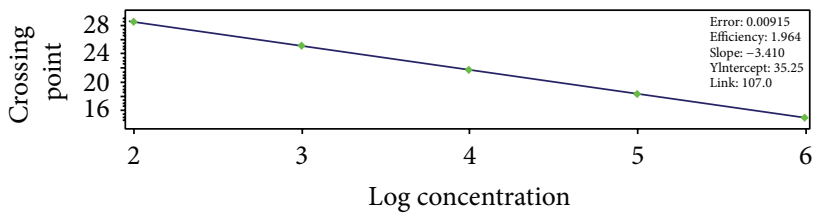

(a)

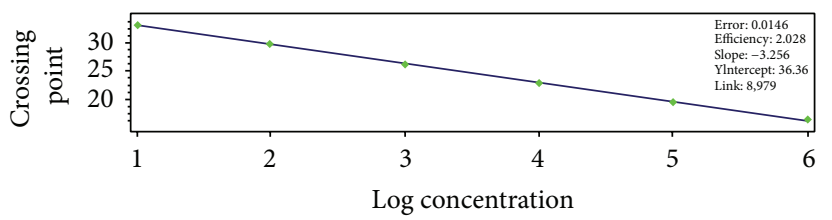

(c)

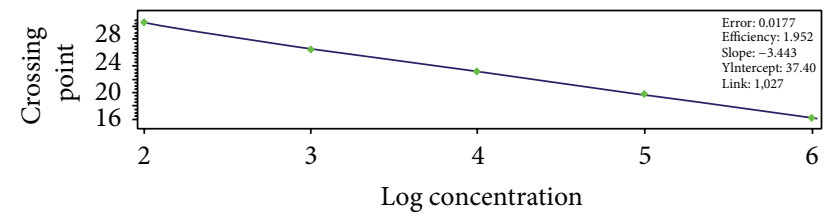

(b)

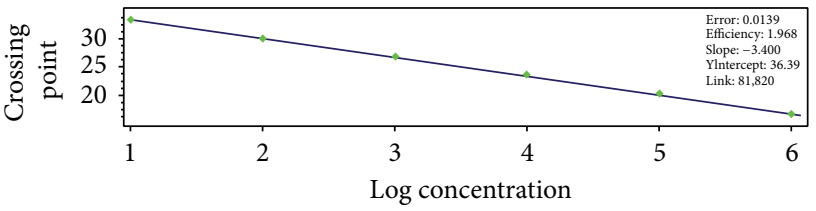

(d)

Figure 2: Standard curves were generated based on Cp values of 10-fold dilutions of plasmid DNA. Regression lines between the Cp $\left(C_{T}\right)$ values and the input concentrations of HP-PRRSV (a) and PRRSV (b) plasmid DNA in real-time RT-PCR detected using SYBR Green I and HP-PRRSV (c) and PRRSV (d) using TaqMan probe, respectively.

10 -fold serially diluted plasmid standards of HP-PRRSV (pMD20-GD) and PRRSV (pMD20-CH1a) were used as templates for sensitivity tests in both conventional PCR and real-time PCR using SYBR Green I and TaqMan probe. The results showed that real-time PCR using both SYBR Green I (Figure 6) and TaqMan probe (Figure 5) can be used to detect concentrations at least $10^{0}$ copies $\mu \mathrm{L}$ of plasmid standards whereas the sensitivity of conventional PCR was only $10^{3}$ copies $/ \mu \mathrm{L}$.

The intra- and interassay reproducibility were evaluated using three replicates of $10^{6}, 10^{4}$, and $10^{2}$ copies $/ \mu \mathrm{L}$ plasmid standards of both pMD20-GD and pMD20-CH1a. Mean and coefficient of variation $(\mathrm{CV})$ for the $C_{T}$ value were calculated. The results showed that neither the CVs of intra-assay nor the CVs of interassay were more than $5 \%$ (Table 2), indicating the reproducibility of the two assays.

Our results showed that real-time PCR using both SYBR Green I and TaqMan probe could be used to simultaneously detect and differentiate HP-PRRSV and PRRSV in China. But the TaqMan probe method had the highest detection rate, whereas the conventional RT-PCR was the lowest. The SYBR Green I real-time PCR assay is timesaving, easy to handle, and highly sensitive. Yang et al. detected the PRRSV and CSFV RNA by SYBR Green I-based quantitative PCR and found that both sensitivity and specificity were equal or superior to conventional RT-PCR [14]. Although Tian et al. developed a rapid SYBR one step real-time RT-PCR for detection of
PRRSV [15], it could not be used for simultaneous detection and differentiation of HP-PRRSV and classical North American type PRRSV (PRRSV). Kleiboeker et al. developed dual labeled probes quantitative PCR, which could simultaneously detect NA- and EU-PRRSV [16]. However, this assay could not simultaneously detect and differentiate between both HPPRRSV and classical North American type PRRSV (PRRSV) strains in China. The TaqMan probe method provided more accurate results than SYBR Green I with melting curve analysis. SYBR Green I real-time PCR assay was simpler, rapider, and lower in cost than TaqMan probe method. In addition to the high specificity, sensitivity, and reproducibility, the realtime PCR assay based on both SYBR Green I and TaqMan probe established by us could recognize coinfection of HPPRRSV and PRRSV. Because the two types of PRRSV isolates coexist in Chinese swine herds, recombination could occur. Therefore, the results provided alternative diagnostic assays in diverse PRRSV epidemiological circumstances.

3.4. Testing of Clinical Samples. To compare and evaluate the developed real-time RT-PCR and conventional RT-PCR, 2 reference strains of H-PRRSV (GD and XH) and N-PRRSV ( $\mathrm{CH}-1 \mathrm{a}$ and $\mathrm{CC})$ and 15,39 , and 477 serum samples were tested. The results were shown in Table 3 . The results of 4 reference strains for real-time PCR assays were consistent with that of conventional RT-PCR method. The results of 


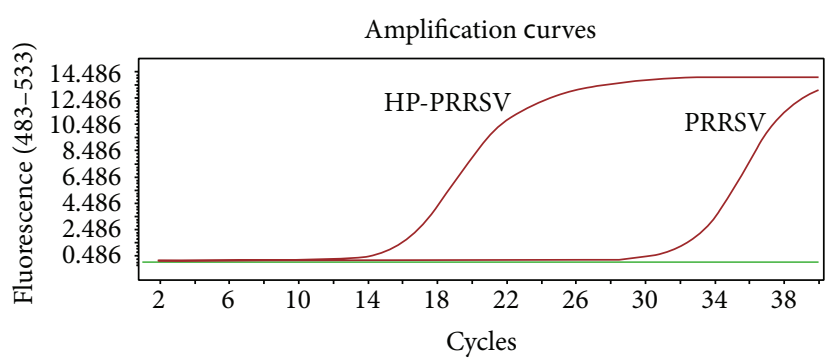

(a)

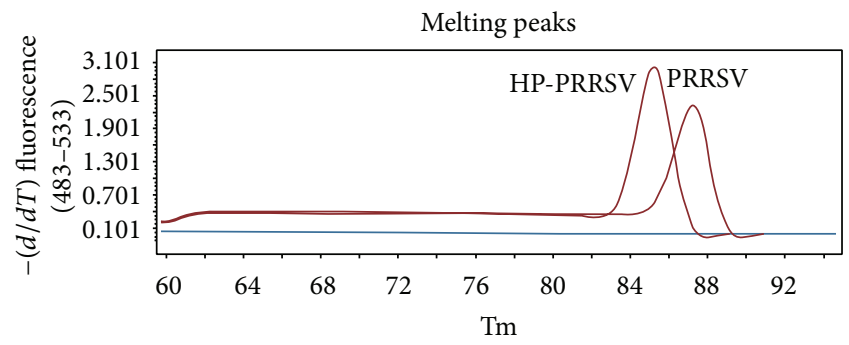

(b)

FIGURE 3: Specific amplification curves and melting curve analysis by SYBR Green I real-time PCR. (a) Specific amplification curves. Fluorescent curves were observed when HP-PRRSV (GD) and PRRSV (CH-la) were used as templates; no fluorescent signals were observed when the templates were other viruses and host cells. (b) Melting curves. Tm of HP-PRRSV $=85.17 \pm 0.12^{\circ} \mathrm{C} ; \mathrm{Tm}$ of PRRSV $=87.27 \pm 0.07^{\circ} \mathrm{C}$.

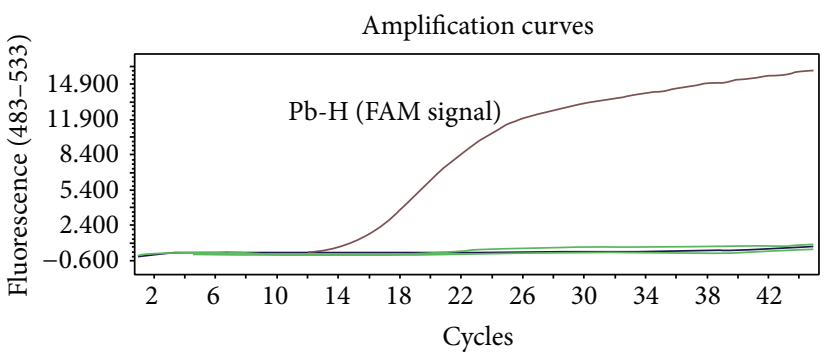

(a)

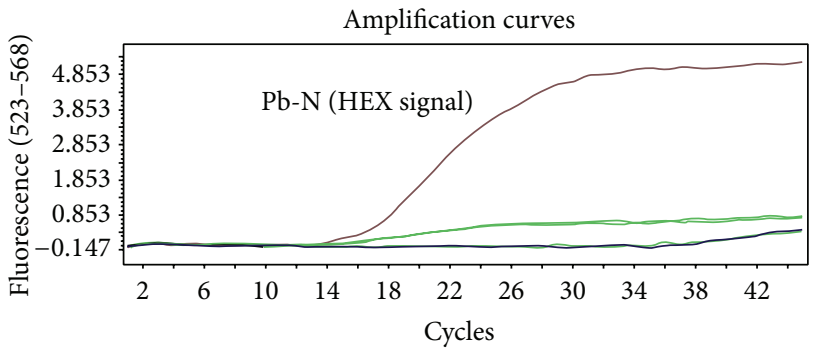

(c)

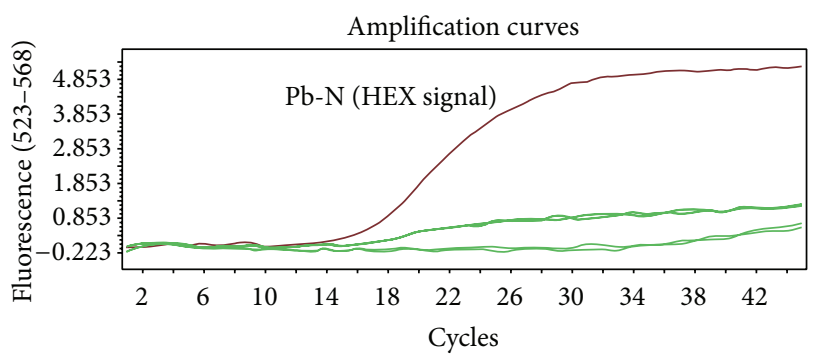

(b)

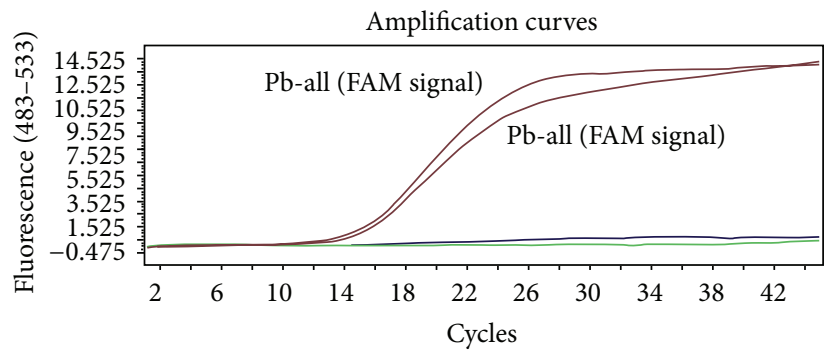

(d)

Figure 4: Specific amplification curves by duplex TaqMan probe real-time PCR. When $\mathrm{Pb}-\mathrm{H}$ (FAM) and Pb-N (HEX) probes were combined in a duplex real-time PCR system, only the FAM fluorescent signal could be observed when the template was GD HP-PRRSV strain, no FAM signal was detected when the templates were $\mathrm{CH}$-la PRRSV strain and other viruses (a), and vice versa, only the HEX signal could be collected when the template was $\mathrm{CH}-\mathrm{la}$ PRRSV strain (b). When Pb-N (HEX) and Pb-all (FAM) were combined in a duplex real-time PCR system, the $\mathrm{Pb}-\mathrm{N}$ (HEX signal) probe could only detect PRRSV strain (c), whereas Pb-all (FAM signal) probe could detect both HP-PRRSV and PRRSV strains (d).

531 serum samples showed that the TaqMan probe real-time PCR had the highest detection rate, whereas the conventional RT-PCR had the lowest detection rate. To evaluate comprehensively the practicality of this assay, clinical samples that span a broader geographical origin should be tested in the future.

\section{Conclusions}

The real-time RT-PCR for simultaneous detection and differentiation of HP-PRRSV and PRRSV by using both SYBR Green and TaqMan probes was developed and validated. Both assays can be used for rapid detection and strainspecific identification of HP-PRRSV and PRRSV. A total of 535 samples were tested by real-time PCR and conventional
RT-PCR. The results of 4 reference strains for real-time PCR assays were consistent with that of conventional PCR method. The results of 531 serum samples showed that the TaqMan probe method had the highest detection rate whereas the conventional RT-PCR was the lowest. The real-time PCR developed based on SYBR Green and TaqMan probe could be used for simultaneous detection and differentiation of HPPRRSV and PRRSV in China, which provided two alternative diagnostic assays in diverse PRRSV epidemiological circumstances.

\section{Conflict of Interests}

The authors declare that there is no conflict of interests regarding the publication of this paper. 


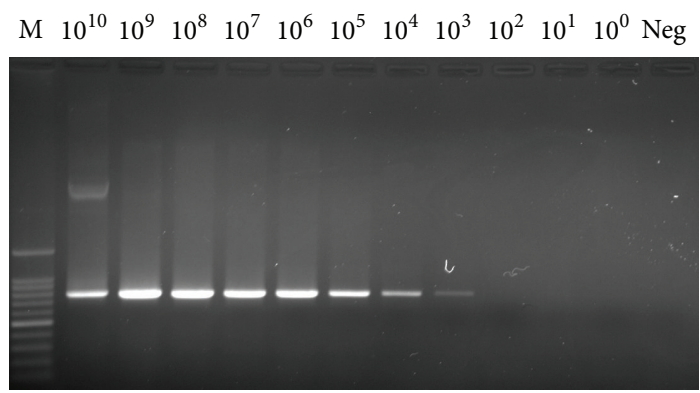

(a)

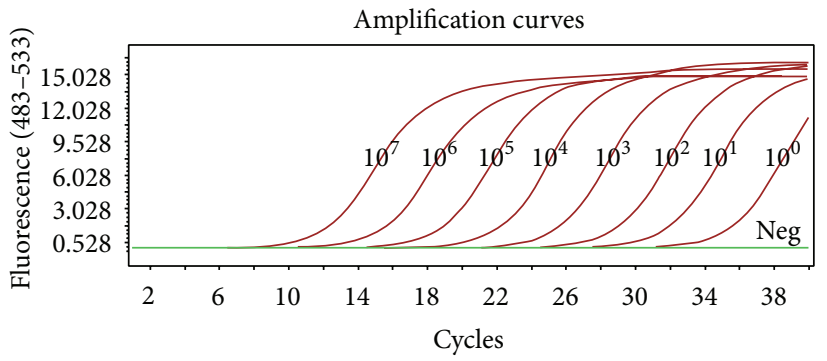

(b)

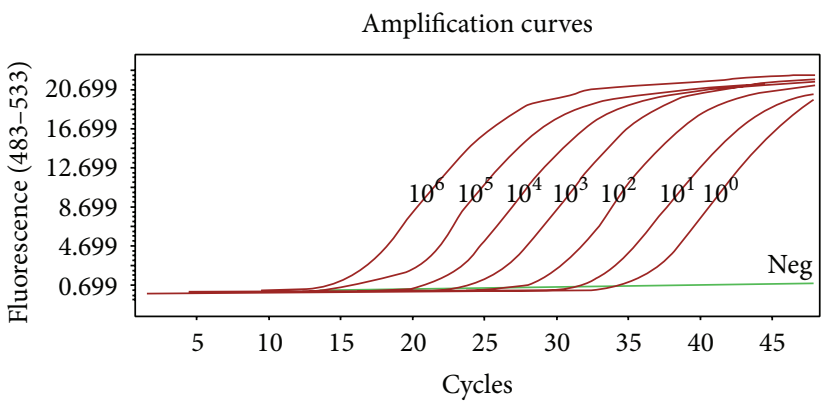

(c)

FIGURE 5: Comparison of sensitivity for HP-PRRSV detection by conventional RT-PCR and real-time PCR. Samples were 10-fold serially diluted plasmid standards of HP-PRRSV. M: 100 bp marker; Neg: negative control.

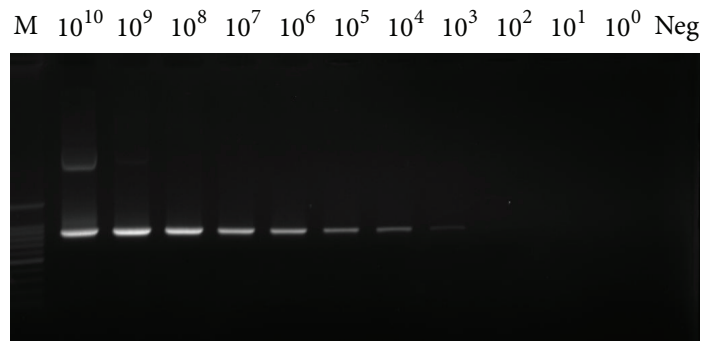

(a)

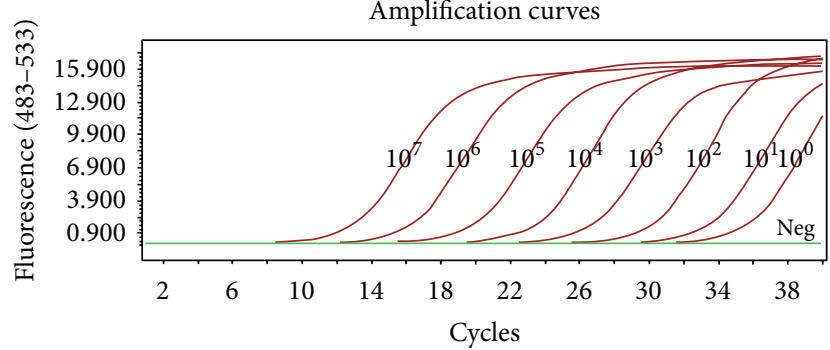

(b)

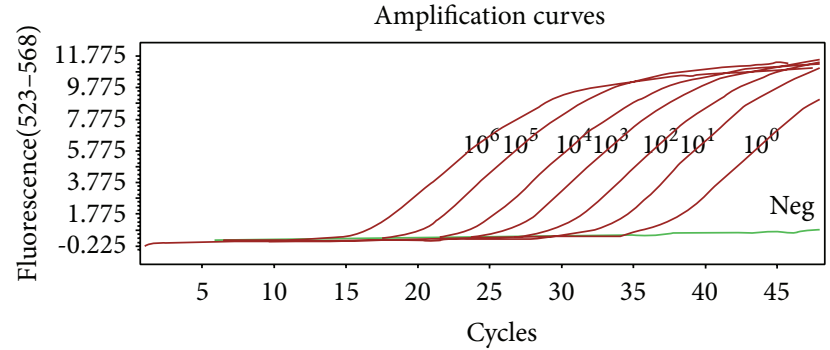

(c)

FIGURE 6: Comparison of sensitivity for PRRSV detection by conventional RT-PCR and real-time PCR. Samples were 10-fold serially diluted plasmid standards of PRRSV. M: 100 bp marker; Neg: negative control.

\section{Acknowledgments}

This work was supported by National Natural Science Foundation Grant no. 31101690 from China, Agriculture Research System Grant no. CARS-36 from China, and Open Project Grant no. SKLBC12 K13 from the State Key Laboratory of Biocontrol.

\section{References}

[1] S. Xiao, J. Jia, D. Mo et al., "Understanding PRRSV infection in porcine lung based on genome-wide transcriptome response identified by deep sequencing," PLoS ONE, vol. 5, no. 6, Article ID el1377, 2010.

[2] K. Tian, X. Yu, T. Zhao et al., "Emergence of fatal PRRSV variants: unparalleled outbreaks of atypical PRRS in China and 
molecular dissection of the unique hallmark," PLoS ONE, vol. 2, no. 6, article e526, 2007.

[3] Y. Li, X. Wang, K. Bo et al., "Emergence of a highly pathogenic porcine reproductive and respiratory syndrome virus in the Mid-Eastern region of China," Veterinary Journal, vol. 174, no. 3, pp. 577-584, 2007.

[4] G.-Z. Tong, Y.-J. Zhou, X.-F. Hao, Z.-J. Tian, T.-Q. An, and H.-J. Qiu, "Highly pathogenic porcine reproductive and respiratory syndrome, China," Emerging Infectious Diseases, vol. 13, no. 9, pp. 1434-1436, 2007.

[5] Y. Feng, T. Zhao, T. Nguyen et al., "Porcine respiratory and reproductive syndrome virus variants, Vietnam and China, 2007," Emerging Infectious Diseases, vol. 14, no. 11, pp. 1774-1776, 2008.

[6] M. Ying, Y. Feng, D. Liu, and G. F. Gao, "Avian influenza virus, streptococcus suis serotype 2, severe acute respiratory syndrome-coronavirus and beyond: molecular epidemiology, ecology and the situation in China," Philosophical Transactions of the Royal Society B: Biological Sciences, vol. 364, no. 1530, pp. 2725-2737, 2009.

[7] D. Normile, "China, Vietnam grapple with âĂIJrapidly evolvingâĂİ pig virus," Science, vol. 317, no. 5841, p. 1017, 2007.

[8] Y.-J. Zhou, X.-F. Hao, Z.-J. Tian et al., "Highly virulent porcine reproductive and respiratory syndrome virus emerged in China," Transboundary and Emerging Diseases, vol. 55, no. 34, pp. 152-164, 2008.

[9] W. Lurchachaiwong, S. Payungporn, U. Srisatidnarakul, C. Mungkundar, A. Theamboonlers, and Y. Poovorawan, "Rapid detection and strain identification of porcine reproductive and respiratory syndrome virus (PRRSV) by real-time RT-PCR," Letters in Applied Microbiology, vol. 46, no. 1, pp. 55-60, 2008.

[10] E. MartÃnnez, P. Riera, M. SitjÃă, Y. Fang, S. Oliveira, and J. Maldonado, "Simultaneous detection and genotyping of porcine reproductive and respiratory syndrome virus (PRRSV) by real-time RT-PCR and amplicon melting curve analysis using SYBR Green," Research in Veterinary Science, vol. 85, no. 1, pp. 184-193, 2008.

[11] A. Wasilk, J. D. Callahan, J. Christopher-Hennings et al., "Detection of U.S., lelystad, and european-like porcine reproductive and respiratory syndrome viruses and relative quantitation in boar semen and serum samples by real-time PCR," Journal of Clinical Microbiology, vol. 42, no. 10, pp. 4453-4461, 2004.

[12] X.-L. Xiao, H. Wu, Y.-G. Yu et al., "Rapid detection of a highly virulent Chinese-type isolate of Porcine Reproductive and Respiratory Syndrome virus by real-time reverse transcriptase PCR," Journal of Virological Methods, vol. 149, no. 1, pp. 49-55, 2008.

[13] S. Xiao, Q. Wang, J. Jia et al., "Proteome changes of lungs artificially infected with H-PRRSV and N-PRRSV by twodimensional fluorescence difference gel electrophoresis," Virology Journal, vol. 7, article 107, 2010.

[14] Z.-Z. Yang, W.-H. Fang, and M. Habib, "First results of detection of PRRSV and CSFV RNA by SYBR green I-based quantitative PCR," Journal of Veterinary Medicine B: Infectious Diseases and Veterinary Public Health, vol. 53, no. 10, pp. 461-467, 2006.

[15] H. Tian, J. Wu, Y. Shang, Y. Chen, and X. Liu, “The development of a rapid SYBR one step real-time RT-PCR for detection of porcine reproductive and respiratory syndrome virus," Virology Journal, vol. 7, article 90, 2010.

[16] S. B. Kleiboeker, S. K. Schommer, S.-M. Lee, S. Watkins, W. Chittick, and D. Polson, "Simultaneous detection of North
American and European porcine reproductive and respiratory syndrome virus using real-time quantitative reverse transcriptase-PCR," Journal of Veterinary Diagnostic Investigation, vol. 17, no. 2, pp. 165-170, 2005. 


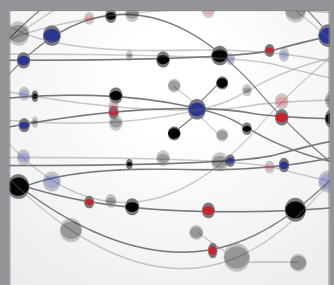

The Scientific World Journal
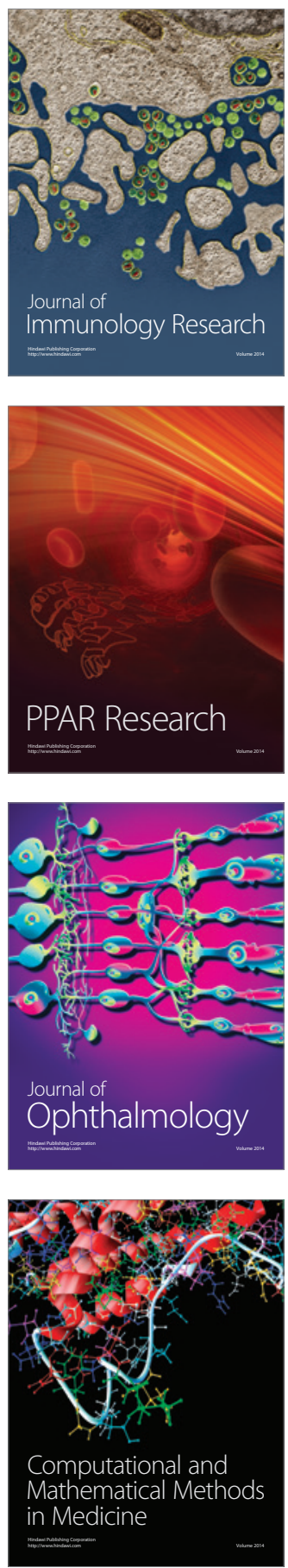

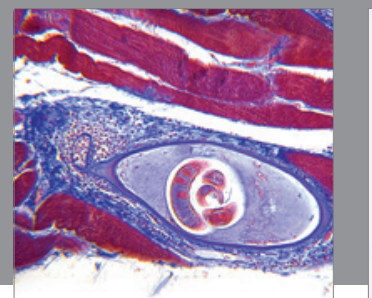

Gastroenterology

Research and Practice
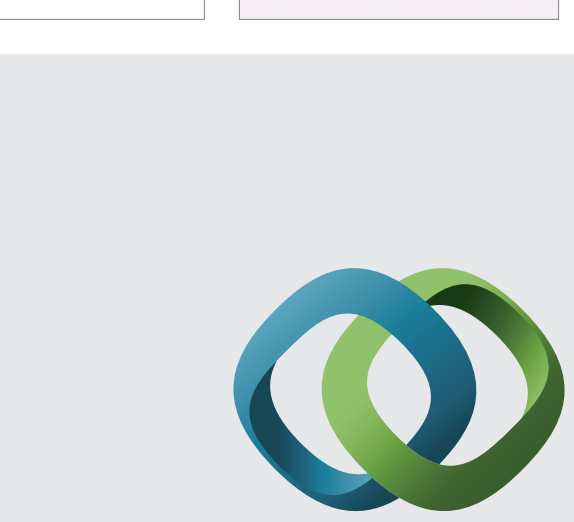

\section{Hindawi}

Submit your manuscripts at

http://www.hindawi.com
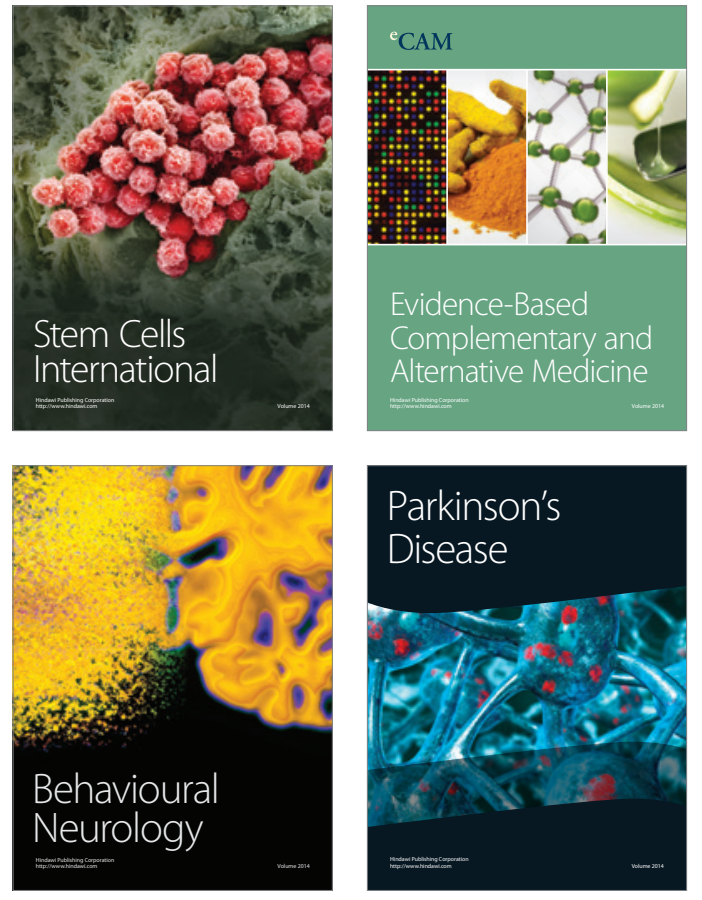


Disease Markers
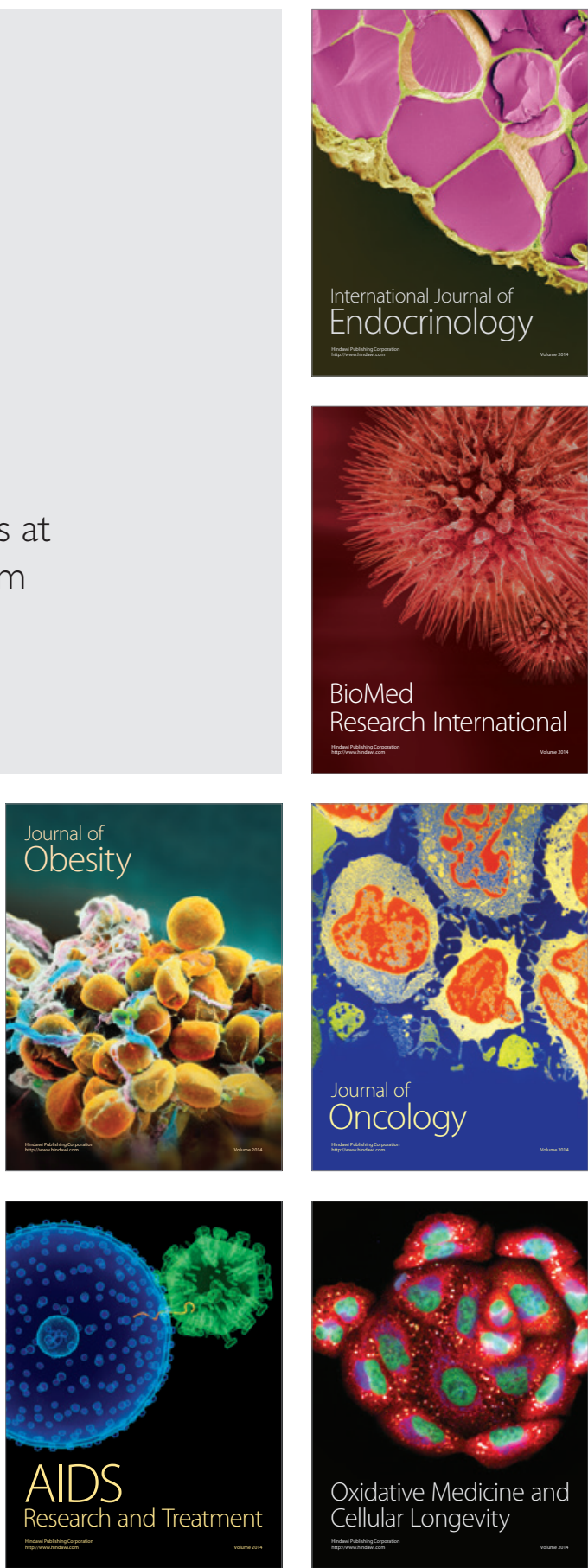